\title{
Chronic constipation: Current management and challenges
}

\author{
Martin Storr MD
}

M Storr. Chronic constipation: Current management and challenges. Can J Gastroenterol 2011;(Suppl B):5B-6B.

Many challenges are associated with the diagnosis and management of patients with chronic constipation. Some of these challenges arise from the currently incomplete understanding of what causes constipation and from the difficulties in diagnosing and classifying the heterogeneous group of patients with chronic constipation. Despite the availability of different treatment options for constipation, an unmet need for drugs in the treatment of patients with chronic constipation remains. This holds especially true for patients who fail an initial treatment. With promising novel drugs either close to approval for the Canadian market or on the horizon, many of these unmet needs may be addressed. The present supplement to The Canadian Journal of Gastroenterology provides an educational overview of the current understanding of the diagnosis, epidemiology, pathophysiology and management of chronic constipation, and summarizes current treatment options in light of current and newly available drugs.

$\mathrm{T}$ he challenges with chronic constipation are multifold and include the terminology of chronic constipation, identifying the pathophysiology of chronic constipation and the best management strategies. The challenges with best management comprise optimal diagnostic and therapeutic approaches for newly diagnosed patients, and for patients who failed initial treatment (1-3).

From the literature, we are left with multiple choices when trying to define chronic constipation in clinical practice. Although the Rome III criteria are currently frequently used in published studies aiming to characterize and define functional constipation, they appear to be rarely used in clinical practice. Following the Rome III criteria, the diagnosis of functional constipation should be based on the presence of symptoms for a minimum of three months. These symptoms include, among others, subjective perception of stool frequency, stool texture and sensation of stool evacuation (4). Despite all attempts from various societies or expert panels, the simple term 'constipation' seems to be preferred in primary practice, while alternative terms or subgroups such as slow transit constipation, functional defecation disorder, pelvic floor disorders and anismus seem to be limited to academic approaches.

In 2011, classification of constipation remains challenging because constipation may be a symptom of numerous underlying etiologies. However, regardless of whether the classification is based on symptoms or on test results, none of the suggested classifications are really suitable for clinical practice. Classifications that are based on a specific test are of limited value because many of the suggested tests are either available only in tertiary centres or are not helpful in translating the test results into a targeted treatment (5). However, the perception of the value of these test-based classifications may change with novel drugs being approved. For example, a motility test may be appropriate to perform if, eventually, the impaired function can be directly targeted by a medication that improves motility. Clinical trials establishing how the different functional tests can be performed in patients

\section{La constipation chronique : La prise en charge et les problèmes courants}

De nombreux problèmes s'associent au diagnostic et à la prise en charge des patients atteints de constipation chronique. Certains de ces problèmes découlent des connaissances incomplètes sur les causes de la constipation et de la difficulté à diagnostiquer et à classer le groupe hétérogène de patients ayant une constipation chronique. Malgré l'accessibilité à diverses possibilités thérapeutiques pour la constipation, il reste des besoins non respectés dans le traitement des patients atteints de constipation chronique. C'est particulièrement vrai pour les patients qui ne réagissent pas au traitement initial. Puisque de nouveaux médicaments prometteurs sont sur le point d'être approuvés au Canada ou sont en cours d'évaluation, bon nombre de ces besoins non respectés pourraient bien être résolus. Le présent supplément du Journal canadien de gastroentérologie fournit un aperçu pédagogique des connaissances actuelles sur le diagnostic, l'épidémiologie, la physiopathologie et la prise en charge de la constipation chronique et résume les possibilités thérapeutiques actuelles, à la lumière des médicaments connus et nouvellement homologués.

with constipation and subsequently guide our decisions toward a specific drug treatment in a meaningful way have yet to be performed. Dr J Gray addresses how chronic constipation is defined and how diagnosis is made in a practical way, and helps us to understand how classifications are best used for patients with chronic constipation.

The burden of chronic constipation to both patients and society is enormous. A prospective study reported that the mean annual health care costs including diagnostic tests and treatment of chronic constipation in a mid-size town in the United States sum up to $\$ 7,522$ per patient per year (6). Due to the above-mentioned high prevalence of constipation, the financial burden is enormous and better treatments would not only improve patient quality of life, but likely also reduce the overall costs by reducing direct and indirect health care costs. Drs MI Pinto Sanchez and P Bercik summarize the present information regarding the epidemiology and burden of chronic constipation and set the stage for the need for powerful drugs in the treatment of chronic constipation.

The pathophysiology of constipation includes multiple changes including those in secretor and motor function of the gastrointestinal tract, central and peripheral control of gastrointestinal function as well as environmental, genetic and comorbidity factors (7-9). Our understanding is still incomplete and far from explaining the complexity of changes that finally result in constipation. Drs C Andrews and M Storr provide an overview on what we currently know about the pathophysiology of chronic constipation and sets the stage needed to understand how new drugs, especially when targeting serotonin (5HT) mechanisms, may improve symptoms of constipation. Changes in colonic motility are believed to be one principal component in the pathophysiology of chronic constipation, and in the past decade, basic scientists have increased our understanding on how colonic motility is controlled in health and disease (8). Translation of this knowledge is still in its infancy and may, among others, be limited by the heterogeneity of patients with chronic constipation. Currently, the majority

Division of Gastroenterology; Department of Medicine, University of Calgary, Calgary, Alberta

Correspondence: Dr Martin Storr, Division of Gastroenterology, Department of Medicine, University of Calgary, 3330 Hospital Drive Northwest, Calgary,

Alberta T2N 4N1. Telephone 403-592-5015, fax 403-592-5090, e-mail gidoc@gmx.com

Received for publication June 5, 2011. Accepted June 10, 2011 
of our understanding of colonic motility in the context of constipation is based on the specific function that a single test captures. Novel drugs that target impaired motility in the colon may be a breakthrough for some patients, especially those in whom impaired motility is the primary target. In this context, better understanding of the 5HT system and the different $5 \mathrm{HT}$ receptor subtypes is important because our current perception of serotoninergic prokinetic drugs is that they were successfully used in the past, but subsequently withdrawn due to dangerous side effects. In the meantime, we have learned that, in contrast to previously used nonselective serotoninergic drugs that are accompanied with multiple side effects, novel 5HT receptor agonists of higher selectivity may be advantageous (10). This holds especially true for prucalupride, a selective $5 \mathrm{HT}_{4}$ receptor agonist that is approved in many European countries and where approval for Canada is pending. Prucalupride, in contrast to previously used 5HT agonists such as cisapride and tegaserod, does not bind to $5 \mathrm{HT}_{1 \mathrm{~B} / \mathrm{D}}$ receptors. It was $5 \mathrm{HT}_{1 \mathrm{~B} / \mathrm{D}}$ receptor activation that caused the cardiac side effects of cisapride and tegaserod, especially the dangerous QT prolongation that consequently resulted in their withdrawal. It is, therefore, encouraging that prucalupride was shown not to prolong the QT interval, and the expectations toward this new option in treating patients with chronic constipation are high (11).

There is no question that constipation is highly prevalent in western societies, with prevalence ranging up to $30 \%$ (4). When using more strict criteria, such as the Rome II criteria, prevalence rates are lower but still in the range of $20 \%$ (12). The reported prevalence appears to be somewhat high, and the number of patients who finally require treatment for their constipation or who fall under the definition of chronic constipation are likely to be lower. Again, different criteria used to define constipation preclude the direct comparison of different epidemiological studies. It is consistent with most of these epidemiological studies to say that chronic constipation is clearly more frequent in older populations; overall, however, chronic constipation is a disease that can affect all ages and sexes (13).

Presently, treatment of constipation remains challenging because patients' and physicians' terminology may be very different, and conducting thoughtful questioning on patients' symptoms and what the patient wants to change may guide our selection of drugs more meaningfully than most of the available functional tests. Those of us who treat patients with constipation know too well that the term 'constipation' covers anything from a stool frequency of less than once a week with normal stool texture, to daily stools with texture being hard as a rock. Without a detailed stool history and discussing reasonable expectations toward treatment, frustration for both patients and physicians is inevitable (14). The Bristol stool scale, aside from being a useful tool to grade stool texture, is a wonderful tool to start such communication and helps to overcome barriers when talking about stool in both involved partners (15). Dr LWC Liu summarizes the currently available treatment options in the treatment of patients with chronic constipation and discusses the options that are available in Canada.

With current medications not addressing all unmet needs, there are huge expectations toward new drug developments. Most of these expectations address benefits including better control of symptoms, being helpful to a broad range of patients with constipation and having stable long-term efficacy. Other expectations address the potential side effects and the overall risk of taking these drugs. Treatment with some drugs was disappointing in the past or they had to be withdrawn from the market. We must accept that novel drugs may not meet all expectations at once, and we have to learn that novel drugs must be carefully used within their approved indication to avoid future disappointments. Treatment of constipation in the future may need to follow stronger algorithms that have yet to be fully developed, with specific drugs being useful in subsets of patients with constipation only. Dr M Camilleri addresses the issue of what to expect from novel drugs, what their potential strengths are and what the best clinical scenario will be to achieve the most benefit when using these drugs.

Finally, having listed all of the challenges associated with chronic constipation, some are left with the feeling that we have good clinical tools to help with the diagnosis and the differential diagnosis of chronic constipation, and that there are good drugs for the treatment of patients with chronic constipation. Dr P Paré will merge the present knowledge and provide some guidance on how to best apply the tools we have.

With novel drugs for the treatment of constipation being introduced, a focused supplement in The Canadian Journal of Gastroenterology appears to be timely and welcome. The authors of the present supplement on chronic constipation intend that the articles serve as a valuable educational tool for all health care providers involved in the treatment of chronic constipation. We designed this supplement to review the current knowledge regarding diagnosis, epidemiology, pathophysiology and management of chronic constipation, discuss the challenges and, finally, give some guidance on how to use this knowledge to optimize management of patients with chronic constipation in daily practice.

\section{REFERENCES}

1. Cook IJ, Talley NJ, Benninga MA, Rao SS, Scott SM.

Chronic constipation: Overview and challenges.

Neurogastroenterol Motil 2009;21(Suppl 2):1-8.

2. Foxx-Orenstein AE, McNally MA, Odunsi ST. Update on constipation: One treatment does not fit all. Cleve Clin J Med 2008;75:813-24.

3. Rao SS. Constipation: Evaluation and treatment of colonic and anorectal motility disorders. Gastrointest Endosc Clin N Am 2009;19:117-39, vii.

4. Longstreth GF, Thompson WG, Chey WD, Houghton LA, Mearin F, Spiller RC. Functional bowel disorders. Gastroenterology 2006;130:1480-91.

5. Rao SS, Singh S. Clinical utility of colonic and anorectal manometry in chronic constipation. J Clin Gastroenterol 2010:44:597-609.

6. Nyrop KA, Palsson OS, Levy RL, et al. Costs of health care for irritable bowel syndrome, chronic constipation, functional diarrhoea and functional abdominal pain. Aliment Pharmacol Ther 2007;26:237-48.

7. Rao SS, Go JT. Update on the management of constipation in the elderly: New treatment options. Clin Interv Aging 2010;5:163-71.

8. Wood JD. Enteric nervous system: Sensory physiology, diarrhea and constipation. Curr Opin Gastroenterol 2010;26:102-8.

9. Dinning PG, Smith TK, Scott SM. Pathophysiology of colonic causes of chronic constipation. Neurogastroenterol Motil 2009;21(Suppl 2):20-30.

10. Bouras EP, Camilleri M, Burton DD, McKinzie S. Selective stimulation of colonic transit by the benzofuran $5 \mathrm{HT} 4$ agonist, prucalopride, in healthy humans. Gut 1999;44:682-6.

11. Lacy BE, Loew B, Crowell MD. Prucalopride for chronic constipation. Drugs Today (Barc) 2009;45:843-53.

12. Higgins PD, Johanson JF. Epidemiology of constipation in North America: A systematic review. Am J Gastroenterol 2004;99:750-9.

13. Talley NJ, Fleming KC, Evans JM, et al. Constipation in an elderly community: A study of prevalence and potential risk factors. Am J Gastroenterol 1996;91:19-25.

14. Paré P, Bridges R, Champion MC, et al. Recommendations on chronic constipation (including constipation associated with irritable bowel syndrome) treatment. Can J Gastroenterol 2007;21(Suppl B):3B-22B.

15. Basseri RJ, Kunkel D, Low K, Conklin JL, Pimentel M. Importance of diarrhea in evaluating constipation in irritable bowel syndrome clinical studies. J Clin Gastroenterol February 2011 (E-pub ahead of print). 


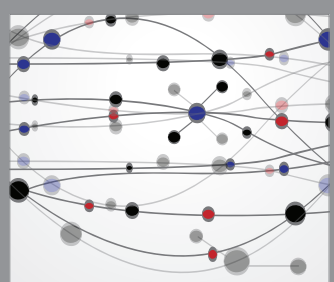

The Scientific World Journal
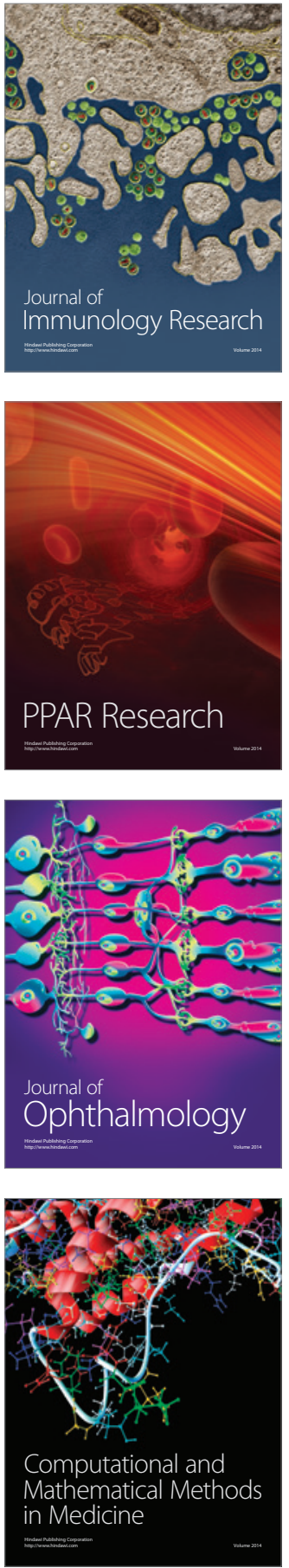

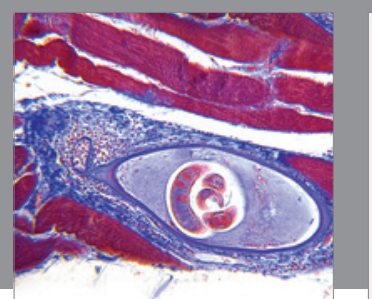

Gastroenterology Research and Practice

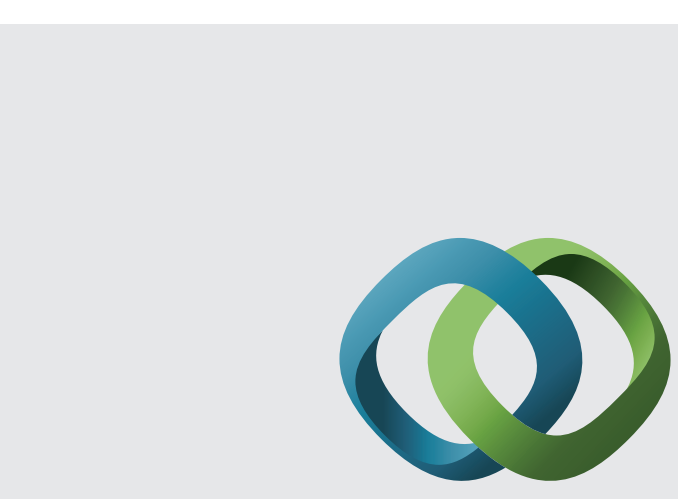

\section{Hindawi}

Submit your manuscripts at

http://www.hindawi.com
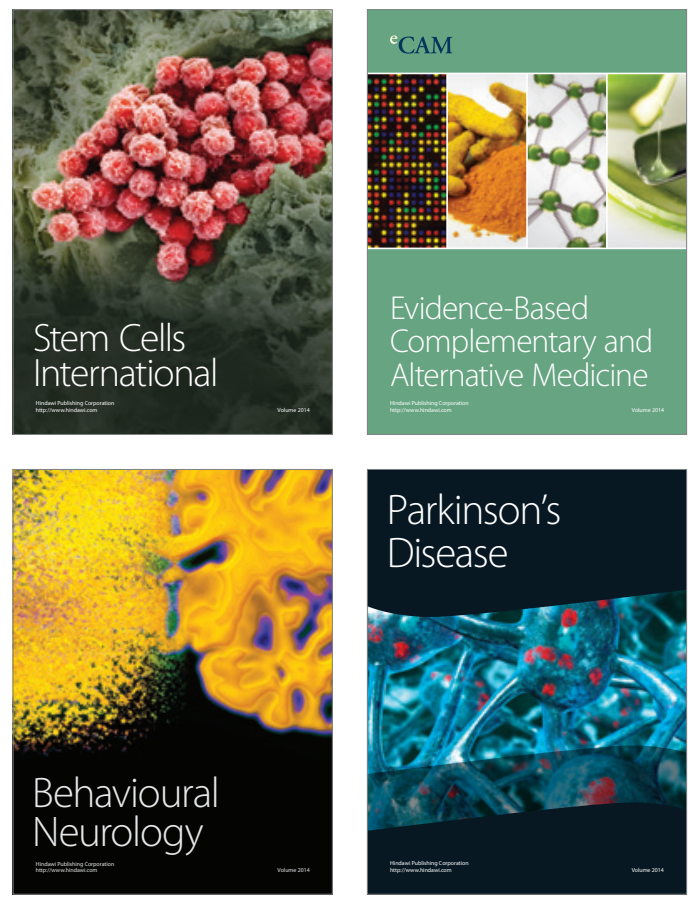
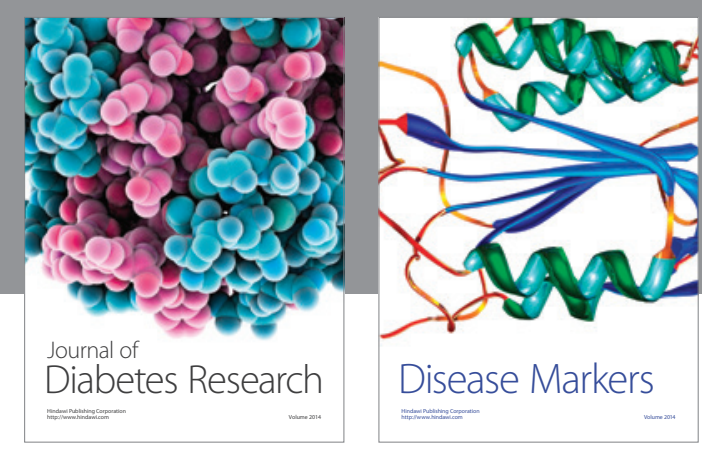

Disease Markers
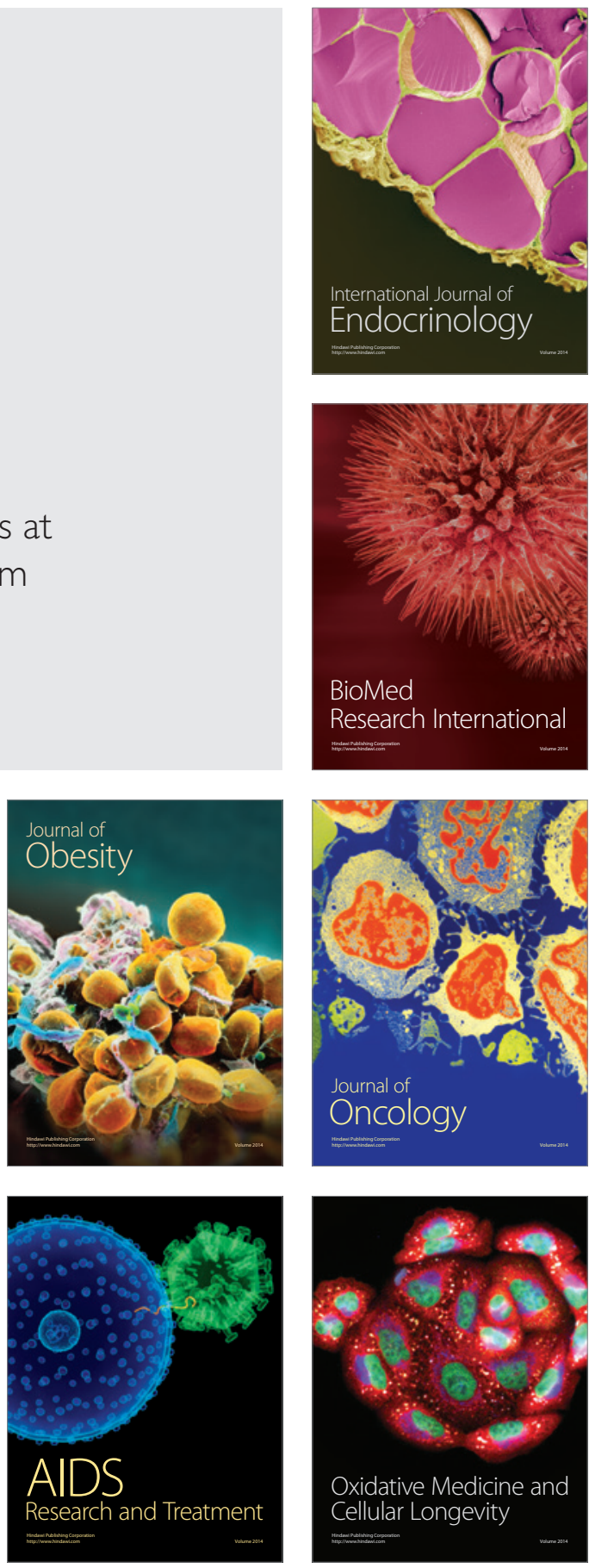